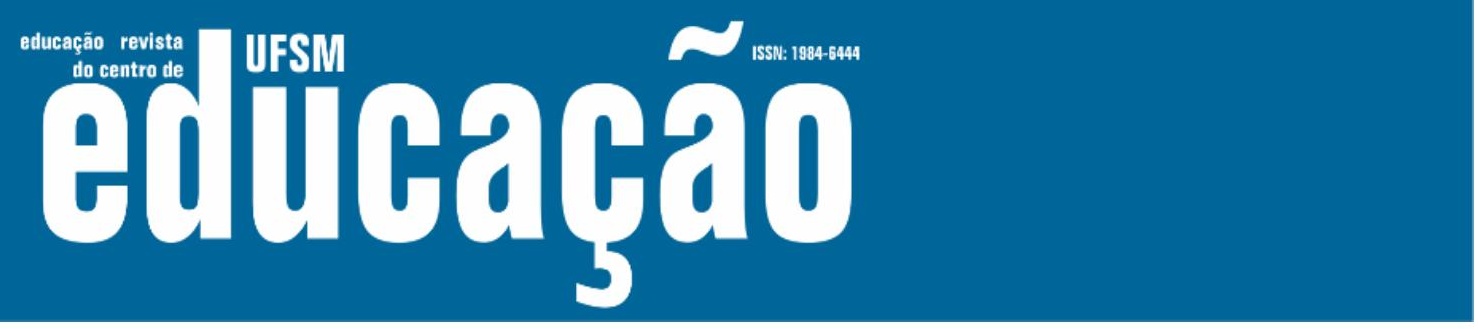

ISSN: 1984-6444 | http://dx.doi.org/10.5902/1984644439519

\title{
O novo Ensino Médio e a liberdade de escolha
}

\author{
The new High School and the freedom of choice
}

\author{
Márden Pádua Ribeiro \\ Professor doutor na Pontifícia Universidade Católica de Minas Gerais, Belo Horizonte, Minas Gerais, \\ Brasil. Assessor Pedagógico do Bernoulli Sistema de Ensino \\ mardendepadua@yahoo.com.br - https://orcid.org/0000-0001-7059-7461
}

Teodoro Adriano Costa Zanardi

Professor doutor na Pontifícia Universidade Católica de Minas Gerais, Belo Horizonte, Minas Gerais, Brasil.

zanardi@pucminas.br - http://orcid.org/0000-0003-4742-9288

Recebido em 13 de agosto de 2019

Aprovado em 15 de julho de 2020

Publicado em 18 de novembro de 2020

\section{RESUMO}

O ensaio aborda a proposta do Novo Ensino Médio a partir de suas promessas de liberdade de escolhas reiteradas aos (às) jovens brasileiros(as), através de intensa propaganda midiática realizada pelo Ministério da Educação. O conceito de liberdade é central e precisa ser desvelado a partir de nossa realidade desigual. Ao dialogar com as propagandas produzidas pelo MEC, o texto da reforma do Ensino Médio e a realidade excludente, buscamos contextualizar como essa proposta curricular pretende desempenhar seu papel no acobertamento de desigualdades que estruturam a sociedade capitalista brasileira. O marco de referência é a concepção de frieza burguesa, de viés crítico desenvolvido por Gruschka, para a compreensão de como se efetiva a indiferença em relação aos destinos dos sujeitos.

Palavras-chave: Ensino Médio; Liberdade; Desigualdades.

\section{ABSTRACT}

This article intends to approach the proposal of a new high school regarding its promises of freedom brought to the youth by the media's intense publicity, made by the ministry of education. The concept of freedom is substantial and needs to be unveiled according to our social issues, such as, inequality. By dialoguing with the commercials produced by "MEC", the base text of the high school reconstruction and the country's excluding reality; I seek to contextualize how this new curriculum proposal intends to cover up the inequalities that structure our capitalist society. The frame of reference is the concept of bourgeois coldness, in the critical view developed by Gruschka, to understand how the indifference regarding the lives of the subjects is built.

Keywords: New High School; Freedom; Inequalities. 


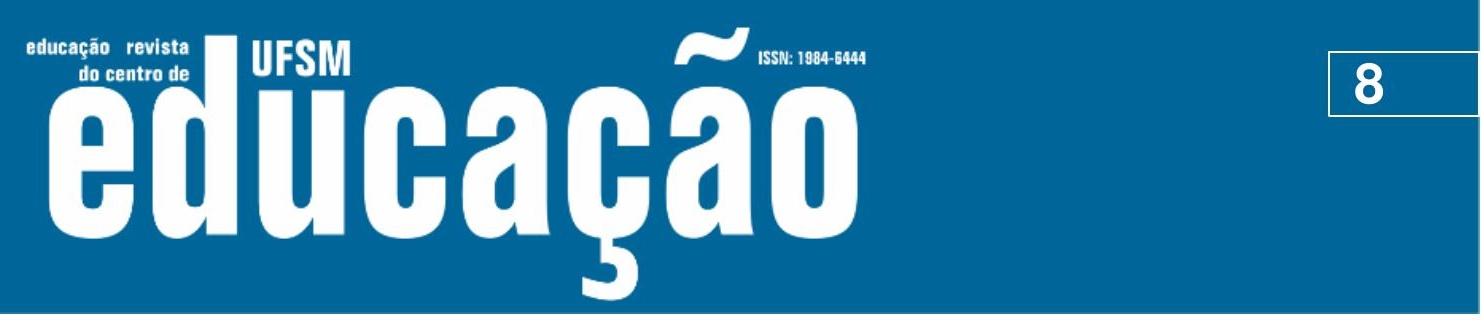

ISSN: 1984-6444 | http://dx.doi.org/10.5902/1984644439519

Física e Química”. Assim, percebeu que teria que ir para São Paulo para cursar o clássico.

Temer, portanto, se viu diante de um itinerário que não se coadunava com seus interesses e estava limitado pela oferta de um só percurso na cidade onde morava. No seu caso, a família teve condições para enviá-lo e sustentá-lo na capital paulista, proporcionando-Ihe a formação que julgavam adequada. Ressaltou a importância desse fato para o prosseguimento nos estudos, pois, como confessou, ficou em "segunda época em Física e Química".

Esse prelúdio serve para iluminar as (im)possibilidades de itinerários que os(as) jovens terão com a implementação do Novo Ensino Médio, pois, em que pese a LDB dispor sobre os itinerários, não há obrigação alguma de a escola oferecer todos eles, nem ao menos dois, para que se possa afirmar que há efetiva escolha na formação.

Essa previsão de escolhas no texto da LDB, não concretiza as opções, pois "o currículo do ensino médio será composto pela Base Nacional Comum Curricular e por itinerários formativos, que deverão ser organizados por meio da oferta de diferentes arranjos curriculares, conforme a relevância para o contexto local e a possibilidade dos sistemas de ensino" (BRASIL, 1996, grifos nossos). A possibilidade dos sistemas de ensino público na atualidade não condiz com o aumento de investimento para o incremento dos percursos formativos, como veremos a seguir.

Assim, a escolha para jovens que residem em pequenas cidades só seria possível, se tiverem condições econômicas de se deslocar para outras cidades que têm escolas com oferta do itinerário desejado. Mesmo para aqueles que residem em grandes cidades não há garantia de oferta de vários itinerários em uma mesma escola.

O que os pais (abastados) do jovem Temer proporcionaram a ele não será viabilizado aos jovens brasileiros, com a reforma do Ensino Médio. As mensagens midiáticas do MEC também se voltam para as experiências de outros países que têm a educação como "prioridade", pois o Novo Ensino Médio teria nessas experiências a sua inspiração. Não pretendemos tocar em comparativos de modelos, mas sim na prioridade que a educação tem para o governo de plantão.

Nunca é demais ressaltar que o Ministério da Educação, autor da proposta, deixará a cargo dos Estados a oferta pelos itinerários em um momento de restrição 


\section{usm

Lado outro, a promessa de igualdade entre as escolas públicas e privadas no atendimento aos itinerários é frustrada pelo próprio texto da reforma, que permite às escolas um currículo misto e, se faça justiça, às públicas e as privadas, ao dispor:

\footnotetext{
Art. 36. O currículo do ensino médio será composto pela Base Nacional Comum Curricular e por itinerários formativos, que deverão ser organizados por meio da oferta de diferentes arranjos curriculares, conforme a relevância para o contexto local e a possibilidade dos sistemas de ensino, a saber:

I - linguagens e suas tecnologias;

II - matemática e suas tecnologias;

III - ciências da natureza e suas tecnologias;

IV - ciências humanas e sociais aplicadas;

$\mathrm{V}$ - formação técnica e profissional.

$(\ldots)$

§ 3‥ A critério dos sistemas de ensino, poderá ser composto itinerário formativo integrado, que se traduz na composição de componentes curriculares da Base Nacional Comum Curricular - BNCC e dos itinerários formativos, considerando os incisos I a V do caput. (BRASIL, 2017, grifos nossos).
}

A reforma chancela itinerários formativos que integrem linguagens, matemática, ciências da natureza e ciências humanas e sociais aplicadas. O que evidencia a possibilidade de um Ensino Médio integrado, que será a via preferencial das escolas privadas, e outro formado por itinerários. A pressão pelos itinerários formativos tem se realizado sobre as redes estaduais de educação, para que se efetive a reforma, consagrando o "desejo" pela "liberdade de escolha" de percursos fragmentados e parcializados.

Fato é que temos mais um "Novo" Ensino Médio que mantêm promessas de liberdade e igualdade, que tocam os corações e mentes dos e das jovens. Mas que, contraditoriamente, coloca-se de forma precária, fragmentada, sem clareza e se insere um uma lógica individualista legitimadora do sucesso ou fracasso dos sujeitos.

\section{Liberdade e igualdade de oportunidades: cada um é ferreiro de sua própria sorte}

O isolamento dos sujeitos, a partir de suas escolhas individuais, é apresentado e naturalizado pelas mensagens distribuídas na promoção do Novo Ensino Médio. Minha escolha, meu desejo e minha vocação são a tônica da aceitação do futuro que se projeta. $O$ individualismo na busca pelo sucesso e a consequente concorrência 


\section{F WEM Gulloará

ISSN: 1984-6444 | http://dx.doi.org/10.5902/1984644439519

É naturalizada e aceita a miséria, a marginalização e a exclusão motivada por um sentimento de autopreservação que nos induz à preservação das estruturas excludentes.

Essa seria a "jaula de aço" (LÖWY, 2004) de onde não poderíamos sair. A busca pela autopreservação e a, consequente, preservação das desigualdades seriam as únicas possibilidades de projeto de vida. Isto implica necessariamente dizer que não há liberdade de escolhas, pois se estamos presos ao individualismo, à desigualdade e à necessária indiferença para seguir adiante, o que existe é o aprisionamento ao imutável.

Com a aceitação que em uma sociedade desigual não há lugar para todos, os desejos giram em torno da liberdade e da igualdade de oportunidades potenciais, como se essas fossem possíveis substantivamente. A liberdade de escolha não se faz concreta sob qualquer ângulo em uma sociedade desigual, ou seja, a igualdade seria o pressuposto para a liberdade.

Melhor explicando: o paradigma iluminista-burguês traz a implicação de uma liberdade formal, pois depende, como explicou Temer, dos recursos econômicos para se efetivar. Assim, o discurso da liberdade de escolha é mais uma falácia que se dissolve nas necessidades materiais e culturais que milhões de jovens brasileiros possuem e não são minimamente atendidas.

Esse Novo Ensino Médio brinca também com a promessa de ingresso no Ensino Superior, quando menos de $25 \%$ dos jovens, de acordo com o monitoramento do Plano Nacional de Educação (PNE) (BRASIL, 2018), conseguem ingressar atualmente. Necessário salientar que esse mesmo monitoramento revela que a via de entrada onerosa é a que mais tem vagas, nas universidades privadas. Além de não existir vagas gratuitas para todos os egressos do Ensino Médio, a oferta se faz preferencialmente em instituições privadas, onde até há vagas, mas com um preço proibitivo para a maioria de nossos(as) jovens. Novamente, a promessa de liberdade de escolha explicitada pelos itinerários se depara com uma realidade seletiva e excludente.

A promessa de Ensino Superior para os(as) concluintes do Ensino Médio é irrealizável, sendo as condições econômicas, a seleção e a meritocracia, as bases 


\title{
usm AutthapaO

ISSN: 1984-6444 | http://dx.doi.org/10.5902/1984644439519

integral, a "ameaça" de um ensino à distância e a ausência de condições mínimas são questões insanáveis quando se discute uma educação de qualidade.

Insanável é a contradição a liberdade individual, igualdade de oportunidades e o sistema estruturalmente desigual. Os apontamentos dos defeitos das propostas (Novo Ensino Médio e BNCC) feitos por um conselheiro, que se encontra no interior do processo, é importante para que seus vícios sejam submetidos à luz do sol. No entanto, isto não se dá não intenção de subverter o fetiche em que se constituem essas propostas, mas tão somente para buscar o seu aperfeiçoamento de modo a torná-la palatável.

A criação de uma via educacional alternativa precisa se colocar diante da lógica do capital; não o fortalecer. Se a disputa é pela melhora do que está posto, estamos fadados à promoção das desigualdades. O que devemos ter presente é que a subversão dessa lógica é o instrumento de luta diante dos remédios apresentados para otimizar a ordem excludente e seletiva. Trabalhar para o sucesso individual e a indiferença em relação aos outros é legitimar os interesses do capital e aprimorar seu metabolismo.

\begin{abstract}
O papel da educação é de importância vital para romper com a internalização predominante nas escolhas políticas circunscritas à "legitimação constitucional democrática" do Estado capitalista que defende seus próprios interesses. Pois também essa "contra-internalização" (ou contraconsciência) exige a antecipação de uma visão geral, concreta e abrangente, de uma forma radicalmente diferente de gerir as funções globais de decisão da sociedade, que vai muito além da expropriação, há muito estabelecida, do poder de tomar todas as decisões fundamentais, assim como das suas imposições sem cerimônia aos indivíduos, por meio de políticas como uma forma de alienação por excelência na ordem existente. (MÉSZÁROS, 2005, p. 61)
\end{abstract}

Na perspectiva de potencialização de uma educação que tenha um papel de "contra-internalização", não se deve resumir ao desvelamento da ordem do capital. Enfrentar a questão da desigualdade é fundamental, mas não contempla todas as questões sociais que a educação escolarizada precisa contemplar.

Como alerta Apple (2017, p. 251), 


\section{usm

ISSN: 1984-6444 | http://dx.doi.org/10.5902/1984644439519

MEC. Novo Ensino Médio 01. Disponível em https://www.youtube.com/ watch?v=ilszjoWWqfA. (00:30). Acesso em: 01 jul. 2018.

MEC. Novo Ensino Médio 02. Disponível em https://www.youtube.com/ watch?v=4pb1 nasqUtQ. (00:30). Acesso em: 01 jul. 2018.

MEC. Comercial MEC Reforma ensino medio - 02 . Disponível em https://www.youtube.com/watch?v=P_1iPX6Ui54. (01:00). Acesso em: 01 jul. 2018.

MEC. Ministério da Educação (novo ensino médio) - Comercial MEC. Disponível em https://www.youtube.com/watch?v=SArnpY9y0QY. (01:00). Acesso em: 01 jul. 2018i.

MEC. Temer discursa sobre "Novo Ensino Médio". Disponível em https://www.youtube.com/watch?v=iik7xEwo8KQ. (52:49). Acesso em: 01 jul. 2018j.

MÉSZAROS, István. Educação para Além do Capital. Trad. Isa Tavares. São Paulo: Boitempo, 2005.

\section{Correspondência}

Márden Pádua Ribeiro - Pontifícia Universidade Católica de Minas Gerais - Av: Dom José Gaspar, 500 - Coração Eucarístico, CEP 30535-901, Belo Horizonte, Minas Gerais, Brasil.

Teodoro Adriano Costa Zanardi - Pontifícia Universidade Católica de Minas Gerais - Av: Itaú, 505 - Dom Cabral, CEP 30535-012, Belo Horizonte, Minas Gerais, Brasil.

This work is licensed under a Creative Commons Attribution-NonCommercial 4.0 International (CC BY-NC 4.0)

\section{Notas}

\footnotetext{
1 Acentuamos o não-reconhecimento da legitimidade da presidência de Michel Temer em razão do Golpe perpetrado em 2016. Vide JINKINGS; DORIA; CLETO (orgs.). Por que gritamos Golpe? São Paulo: Boitempo, 2016.

${ }^{2}$ Vale notar que o mesmo conselheiro votou pela aprovação da Base Nacional Comum Curricular da Educação Infantil e do Ensino Fundamental ao contrário das conselheiras Márcia Ângela da Silva Aguiar, Aurina Oliveira Santana e Malvina Tania Tuttman ${ }_{2-}$ que apresentaram seu voto pela rejeição.
} 